\title{
INFRAESTRUCTURA \\ MORAL DEL MERCADO \\ Y DEMOCRACIA \\ REFLEXIONES A PARTIR \\ DE ADAM SMITH
}

Enrique Serrano*

$\mathrm{E}_{\text {s un lugar común asociar el nombre }}$ de Adam Smith y la noción de mano invisible, utilizada por él, con la ideología del libre mercado. Sin embargo, muy pocos de los defensores y detractores de esta ideología conocen la complejidad del proyecto teórico de este autor, así como el sentido de dicha noción. En la mayoría de los casos se pasa por alto que los argumentos desarrollados en $L a$ riqueza de las naciones (RN), presuponen el análisis de la formación de la conciencia moral, expuesto en la Teoría de los sentimientos morales (TSM). De hecho, durante mucho tiempo se habló del problema de Adam Smith, porque, aparentemente, existe una incoherencia entre el principio de la simpatía, en el que se sustenta la TSM, y el principio del amor propio (self-love), que representa uno de los conceptos centrales de la RN. El problema que percibe esta interpretación es consecuencia de no tomar en cuenta la relación de sucesión que existe entre estas dos obras. Smith no pretende desligar el ámbito económico de la moral, ni aboga por un mercado ajeno a las regulaciones políticas. Por el contrario, su objetivo es explicar la génesis de una moral racional y,

* Profesor de tiempo completo, UAM-Iztapalapa. 
con ella, de las condiciones institucionales que hacen posible el desenvolvimiento de una economía de mercado.

Para comprender el proyecto teórico de Adam Smith es menester, ante todo, considerar el contexto polémico en el que surge. En la TSM, él afirma que uno de sus propósitos es refutar la odiosa doctrina del Sr. Hobbes, porque, aunque la intención de este último había sido liberar la conciencia de los seres humanos de los poderes eclesiásticos, al mismo tiempo, consideraba que la única alternativa era el sometimiento de los individuos a los poderes civiles. Para Hobbes no "hay una norma común de lo bueno y lo malo que se derive de la naturaleza de los objetos mismos" (Leviatán I, 6). Por ello, el estado de naturaleza, esto es, aquella situación que impera en las sociedades donde no existe un orden civil, se caracteriza por una guerra constante, en la cual los contendientes no pueden llegar a ningún acuerdo. Desde su perspectiva, la única posibilidad de superar esa situación consiste en que los seres humanos, gracias a la experiencia de los males que acompañan a la lucha constante, acepten subordinarse a un Estado, capaz de imponer las normas que deben regir sus conductas.

Locke ya había advertido que esta apuesta por la seguridad, en detrimento de la libertad, resultaba insensata, pues los individuos quedaban inermes ante un poder que carecía de controles. Ello sería como querer protegerse de las mofetas y los zorros, refugiándose en la jaula del león. Sin embargo, para superar el relativismo moral del que partía Hobbes, Locke apelaba a una ley natural, cuyo fundamento no quedaba claro. Ante ello, al igual que Hume, Smith se propone demostrar que si bien las distinciones morales son convencionales, un mero artificio social, no por ello son arbitrarias y mucho menos el producto de la decisión de un poder soberano. Su estrategia consiste en abandonar la perspectiva abstracta del contractualismo, para seguir una argumentación histórica. Se trataba de demostrar la posibilidad que tienen los seres humanos de formarse moralmente gracias a la propia dinámica social (en cierta manera, esta tesis se insinúa ya en la teoría de Hobbes). La explicación histórica se manifiesta como un arma con gran poten- 
cialidad frente a las pretensiones desmedidas tanto de la metafísica tradicional, como del decisionismo ajeno a las exigencias racionales.

\section{La historia conjetural}

A esta clase de investigación filosófica, que no tiene nombre apropiado en nuestro lenguaje, me tomaré la libertad de llamarla historia teórica o conjetural; una expresión que coincide bastante en su significado con el de historia natural, según lo emplea el Sr. Hume, y con aquella que algunos escritores franceses han llamado histoire raisonnée.

Dugald Stewart

El método que Adam Smith contrapone al contractualismo, consiste en tomar dos hechos históricos para reconstruir, a través de una narración verosímil, los pasos que fueron necesarios para llegar de uno a otro. Esta narración no pretende ser verdadera, es decir, adecuarse a la complejidad del devenir histórico. Su objetivo es ofrecer un modelo (reducir complejidad), para adentrarse, posteriormente, a la diversidad empírica. ${ }^{1}$ Se trata de tomar distancia, en un primer momento, de la experiencia, para preservar la coherencia lógica. Una vez establecido una línea de investigación se busca aproximarse al nivel empírico, agregando otras variables. El objetivo es hacer posible un análisis racional de la historia, sin perder de vista que ésta es el reino de la particularidad y la contingencia.

La narración histórica de Smith parte del contraste que existe entre las capacidades productivas de las sociedades situadas en la llamada etapa ruda y las sociedades modernas. Dicha disparidad conduce de inmediato a preguntar: ¿Cómo es posible ese notable incremento en la

${ }^{1}$ En su Historia de la Astronomía (IV, 35) Smith sostiene: "Ninguna cosa puede ser demostrada si no se aprende a renunciar a la evidencia de los sentidos, para preservar la coherencia de las ideas en la imaginación." Esta tesis es el antecedente de la teoría de los tipos ideales de la economía neoclásica y de la sociología de Max Weber. 
riqueza de las naciones? La respuesta a esta interrogante se encuentra en el libro primero de la RN: La causa del aumento de la capacidad productiva de la sociedad es el desarrollo de la división del trabajo. Ello se debe, principalmente, a tres factores: 1) La mayor destreza que adquieren los individuos cuando cada uno se dedica a una sola actividad (especialización). 2) El tiempo que se ahorra con la división del trabajo (punto del que parten las técnicas de administración moderna). 3) El análisis o descomposición del proceso de trabajo en sus movimientos simples hace posible sustituir a los trabajadores por máquinas. El desarrollo de la división del trabajo es, a su vez, un efecto de la propensión espontánea de los seres humanos al intercambio; propensión ligada al lenguaje.

Esta división del trabajo, que tantas ventajas reporta, no es en su origen efecto de la sabiduría humana, que prevé y se propone alcanzar aquella general opulencia que de ella se deriva. Es la consecuencia gradual, necesaria aunque lenta, de un cierta propensión de la naturaleza humana que no aspira a una utilidad tan grande: la propensión a permutar, cambiar y negociar una cosa por otra. (...) No es nuestro propósito, de momento, investigar si esta propensión es uno de esos principios innatos en la naturaleza humana, de los que no puede darse una explicación ulterior, o si, como parece más probable, es la consecuencia de las facultades discursivas y del lenguaje. (RN p. 16)

A partir de la tesis respecto de que la unidad social es generada por el sistema de intercambios, tanto de mensajes como de bienes, Smith se propone investigar la génesis de las condiciones que hicieron posible la expansión del mercado, el cual, por su parte, permite superar los obstáculos al desenvolvimiento de la división del trabajo. "Así como la facultad de cambiar motiva la división del trabajo, la amplitud de esta división se halla limitada por la extensión de aquella facultad o, dicho en otras palabras, por la extensión del mercado." (RN p. 20) Precisamente, el tema de la TSM es analizar los pasos que permitieron crear, a través de un proceso de larga duración, la compleja infraes- 
tructura normativa que hace posible el adecuado funcionamiento del sistema mercantil.

Las sociedades que se hallan en la llamada etapa ruda (tradicionales) se encuentran constituidas por diversas unidades productivas, organizadas a través de vínculos de parentesco, las cuales tienden a la autosuficiencia. Por eso, en ellas el intercambio de bienes juega un papel marginal; se produce para consumir, no para intercambiar. La unidad de estas sociedades depende básicamente de un intercambio comunicativo sustentado en un consenso normativo amplio, es decir, la integración social es posible porque sus miembros comparten un sistema de valores. Normalmente es en el discurso religioso donde se condensan los valores que mantienen la cohesión social, ya que el aura de lo sacro permite protegerlos de la disidencia. Son, por tanto, sociedades en las que no existe un amplio espacio para la pluralidad, ni para la libertad individual.

El estímulo recíproco entre la propensión al intercambio y la división del trabajo crea el proceso que erosiona lentamente las bases en las que se sustentan las sociedades tradicionales. La expansión del mercado es el disolvente de los elementos que mantienen la cohesión de este tipo de sociedades. Sin embargo, la división del trabajo implica que cada individuo depende de la actividad productiva de los otros, la mayoría de los cuales no mantiene un vínculo afectivo con él. De esta manera, la integración social ya no depende, fundamentalmente, de las relaciones personales, sino del intercambio de mercancías. En las sociedades modernas se aplica el multicitado texto: "No es la benevolencia del carnicero, del cervecero o del panadero la que nos procura el alimento, sino la consideración de su propio interés. No invocamos sus sentimientos humanitarios, sino su amor propio; ni le hablamos de nuestras necesidades, sino de sus ventajas." (RN p. 17) La independencia respecto a los tradicionales lazos de dependencia personal se obtiene pagando el costo de una dependencia a mecanismos impersonales de integración, ejemplificados por el mercado. A pesar de ello, como veremos más adelante, Smith no sostiene que las sociedades civilizadas puedan prescindir de un consenso normativo como parte 
de su proceso de integración. Lo que sucede es que este consenso ya no tiene un carácter amplio, ni se refiere a formas de vida, sino que se limita a las condiciones de justicia que hacen posible la convivencia en contextos plurales.

Adam Smith nunca pierde de vista que su narración conjetural se mueve en un nivel de abstracción muy elevado, por lo que, si bien puede explicar ciertos aspectos de la evolución social, nunca podrá dar cuenta de la complejidad del devenir histórico y de las variaciones que encontramos en él. De ahí, que no se apresure a sacar conclusiones, pues falta tomar en cuenta una gran cantidad de variables. Aunque en teoría el desarrollo de la división del trabajo y el sistema mercantil crean la posibilidad de incrementar la productividad, hasta lograr, incluso, que la abundancia se difunda a todos los estratos sociales, ese efecto benéfico no se obtiene de manera automática. De hecho, advierte que la división del trabajo y el mercado producen una serie de desventajas que pueden llevar a resultados distintos al que se ha planteado. Muchas de las críticas, en términos de alienación y/o enajenación, que encontramos en Hegel y Marx, ya están presentes en su teoría.

Con el progreso en la división del trabajo, la ocupación de la mayor parte de las personas que viven de su trabajo, o sea la gran masa del pueblo se reduce a muy pocas y sencillas operaciones; con frecuencia, a una o dos tareas. (...) Un hombre que gasta la mayor parte de su vida en la ejecución de unas pocas operaciones muy sencillas, casi uniformes en sus efectos, no tiene ocasión de ejercitar su entendimiento o de adiestrar su capacidad inventiva en la búsqueda de varios expedientes que sirvan para remover dificultades que nunca se presentan. Pierde así, naturalmente, el hábito de aquella potencia, y se hace todo lo estúpido e ignorante que puede ser una criatura humana. (RN p. 687)

Para contrarrestar este inconveniente Smith recomienda que el gobierno gaste en educación, pues la ignorancia y la estupidez no sólo repercute en las posibilidades de la vida individual, sino también produce enormes riesgos en la vida social. 
Aun cuando el Estado no obtuviese ventaja de la instrucción de las clases inferiores del pueblo, merecería su atención el propósito de lograr que no fuesen del todo ignorantes; pero nadie duda que saca, además, considerables ventajas de la instrucción de aquellas gentes. Cuanto más instruidas estén, menos expuestas se hallarán a las desilusiones traídas por la ligereza y la superstición, que frecuentemente ocasionan los más terribles trastornos entre las naciones ignorantes. (RN p. 692)

Para permitir la introducción de un mayor número de variables y, con ello, aproximarse al nivel empírico, Smith acude en sus Lecciones de Jurisprudencia (LJ) a la teoría de los cuatro estadios expuesta, entre otros, por Puffendorf y por varios miembros de la denominada Escuela Escocesa. "Hay cuatro estados distintos por los que la humanidad ha pasado: $1^{\circ}$ La era de los cazadores. $2^{\circ}$ La era de los pastores. $3^{\circ}$ La era de la agricultura y $4^{\circ}$ La era del comercio." (LJ p. 47) Evidentemente, éste sigue siendo un esquema muy simplificado de la historia, pero hace posible percibir la influencia de otros elementos en el desarrollo de las sociedades, como es el papel que han jugado los diversos tipos de organización política. En la lección del martes 8 de marzo de 1873 se destaca que la ruina de la nobleza (debido, entre otros factores, a su propensión al gasto suntuario) dio lugar al poder absoluto del rey. Si bien el Estado absolutista hizo posible una atmósfera propicia para la expansión del mercado, en la mayoría de las sociedades ese tipo de organización del poder también creó numerosos obstáculos al intercambio mercantil. En cambio, en Inglaterra, a pesar de la centralización del poder político implícita en la formación del Estado-Nación, se logró un cierto control del poder del monarca, gracias a la tradición constitucionalista que se remonta, por lo menos, a la Carta magna. Este sistema de libertad propició que el Estado fomentara de una manera más decidida y eficaz el progreso de las manufacturas y el comercio con otras naciones.

De acuerdo con este breve señalamiento histórico los efectos positivos de la división del trabajo y del mercado requieren de condiciones políticas y jurídicas, las cuales se encuentran estrechamente relacio- 
nadas con la formación moral de los individuos. El llamado sistema de libertad natural no es un producto espontáneo del sistema de intercambio mercantil; por el contrario, para que el mercado pueda ser la expresión de la libertad individual requiere de una infraestructura moral, objetivada en un orden institucional. Sin un marco de justicia el mercado conduce a un estado de naturaleza como el descrito por Hobbes y, en esa guerra, permanente se tiende a la formación de monopolios que anulan la competencia mercantil y sus posible efectos benéficos. A diferencia de la ingenua noción de progreso que se extenderá en el siglo XIX, para Adam Smith no hay una conexión necesaria entre progreso técnico, propiciado por la dinámica mercantil, y progreso moral y político.

\section{Análisis genético de la conciencia moral}

Smith se enfrenta a la tradicional concepción platónica de la división del trabajo, para la cual las ventajas que se pueden obtener de ella depende de su adecuación a las diferentes funciones que por naturaleza puede cumplir cada individuo. Sin negar que existen ciertas aptitudes naturales, Smith considera que básicamente todos los seres humanos han nacido iguales y que los beneficios de la división del trabajo dependen más de la educación y el adiestramiento, que de la naturaleza. De esta manera, rechaza cualquier intento de apelar a un supuesto orden natural para fundamentar la moral; ${ }^{2}$ su estrategia, al igual que Hobbes, consiste en tomar como punto de partida una descripción realista del comportamiento humano. Sin embargo, para Smith la descripción hobbesiana es parcial, incompleta, lo cual conduce a considerar que los individuos no son aptos para convivir de manera civilizada en la sociedad, a menos que exista un poder civil que los someta a su domi-

2 Aunque Smith habla en ocasiones de una armonía natural, nunca asume que del conocimiento de esa armonía pueda deducirse la manera en que deben comportarse los seres humanos. Se trata más bien, de una hipótesis que permite suponer un orden, con la finalidad de orientar la investigación empírica. 
nio. Desde su punto de vista: "Por más egoísta que se pueda suponer al hombre, existen evidentemente en su naturaleza algunos principios que le hacen interesarse por la suerte de los otros, y hacen que la felicidad de éstos le resulte necesaria, aunque no derive de ella más que el placer de contemplarla." (TSM p. 49)

A pesar de ello, el objetivo no es contraponer a la tesis de Hobbes respecto a que los seres humanos son inocentemente peligrosos, la de que los individuos son benevolentes con sus congéneres. Aunque la benevolencia puede estar presente en diversos comportamientos, ella no es el factor más importante o predominante de las acciones. El punto fuerte de la posición teórica de Smith consiste en destacar que lo descrito por Hobbes y Mandeville como egoísmo, es un sentimiento más complejo, o quizá sea mejor decir que se trata de dos sentimientos: egoísmo (selfishness) y amor propio (self-love). Mientras el primero se opone a las exigencias morales, el segundo representa el punto de partida para el desarrollo del sentido moral. Esto se reconoce ya, de manera implícita, en la ética cristiana cuando se afirma: Ama a tu prójimo como a ti mismo. El amor propio representa el motivo más poderosos o predominante en las acciones humanas. "Es indudable que por naturaleza cada persona debe primero y principalmente cuidar de sí misma, y como cada ser humano está preparado para cuidar de sí mejor que ninguna persona, es adecuado y correcto que así sea." (TSM p. 180)

El amor propio impulsa a los individuos a interesarse por los otros, porque cada uno encuentra en sus semejantes los medios para acceder a sus fines; pero, a diferencia del egoísmo, no se reduce al otro a un simple medio. Podemos decir que el egoísmo es resultado de una degeneración del amor propio, en la que se pierde la dimensión de la reciprocidad. Mientras el egoísmo crea barreras entre los seres humanos, en el amor propio se encuentra la base de la sociabilidad, a saber: La simpatía. Esta última no es un sentimiento diferente a los demás, sino un efecto que surge del acuerdo de sentimientos entre un espectador y un actor. Sentimos simpatía cuando existe una comunicación y coordinación de sentimientos con el otro. "Cualquiera sea la causa de la 
simpatía, cualquiera sea la manera en que sea generada, nada agrada más que comprobar que otras personas sienten las mismas emociones que laten en nuestro corazón y nada nos disgusta más que observar lo contrario." (TSM p. 57)

La simpatía conduce a que el espectador apruebe las acciones del actor. El espectador puede simpatizar con las causas que motivaron la acción o bien con los efectos de la acción. En el primer caso se habla de una simpatía directa, pues en ella se establece una coincidencia con los motivos del actor. En el segundo caso, se denomina simpatía indirecta, porque en ella no se coincide con los motivos, sino con los efectos de la acción, por ejemplo, se da una simpatía con el sentimiento de agradecimiento de la persona que fue objeto de una acción benevolente. La simpatía directa define la corrección o incorrección de la acción, por su parte, la simpatía indirecta determina su mérito o demérito. Hume platea que la aprobación moral de las acciones depende de su utilidad; en contraste con él, Smith destaca que la definición de la utilidad presupone una elaborada intervención de la razón para calcular los efectos producidos por la acción, mientras que la aprobación moral es inmediata. Ello indica que la aprobación moral se basa en la simpatía directa, esto es, en los motivos de las acciones. De esta manera, Smith se distancia de lo que más tarde se denominará la tradición utilitarista.

Smith no niega que la utilidad representa un elemento importante en la evaluación de las acciones. Como hemos dicho para él los efectos de la acción establecen su mérito o demérito; incluso reconoce, como veremos más adelante, que los seres humanos tienden a confundir la causa eficiente con la causa final, lo que lleva a situar el peso de los juicios morales en los efectos, más que en los motivos. Pero ello es un error, ya que gran parte de las consecuencias de la acción no pueden ser controladas por los actores; podemos decir que en la definición de los efectos de la acción interviene el azar, entendido como todos aquellos factores que trascienden la conciencia del actor. Pensemos en un caso construido ad hoc para explicar el sentido de esta tesis de manera simple: Una persona se propone matar a otra que camina distraída, pero falla el disparo. Sin embargo, el estruendo del tiro le permitió a 
la potencial víctima reaccionar y evitar caer en un hoyo que estaba en su camino. La acción de disparar fue útil, pero no por ello es moralmente correcta.

Smith sabe que las situaciones reales son más complejas y que la evaluación de los actos implica un proceso complejo en donde intervienen diversos factores, entre ellos, tanto las intenciones, como las consecuencias. Por ello, él aboga por una ética que haga compatibles el punto de vista deontológico y el teleológico o bien por la conjunción de una ética de la convicción y una ética de la responsabilidad; siempre y cuando se tome en cuenta que para definir correctamente la aprobación moral se debe situar la prioridad en los motivos que impulsan las acciones, ya que éstos dependen de la voluntad del actor.

Cuando se afirma que la aprobación se basa en la simpatía, de inmediato aparece el problema de que el observador carece de la experiencia de los sentimientos del actor. Existe una distancia irreductible entre el actor y el observador, pues cada sujeto se encuentra encerrado irremediablemente en su propia sensibilidad. Gracias a la imaginación nos podemos situar en el lugar del otro, pero dicha facultad únicamente le permite al observador representarse sus propias sensaciones si estuviera en el lugar del otro. Dicho en otras palabras, la identificación con el otro a través de la imaginación implica un límite, pues ella no puede transportarnos fuera de nosotros, "nuestra simpatía hacia la tristeza o la alegría de otro es sumamente imperfecta". Como sostiene Jean-Pierre Dupuy: "La simpatía presupone la separación de los seres, mitigada por el trabajo de la imaginación" (1998, p. 96). En ciertos casos la imperfección de la simpatía, paradójicamente, la hace posible, como sucede cuando sentimos conmiseración por el loco que se siente satisfecho con su suerte o cuando nos sonrojamos ante la desfachatez y la grosería del comportamiento de un individuo que no es consciente del carácter inapropiado de su comportamiento. Aquí no existe una concordancia de sentimientos, sino una proyección de los sentimientos propios en el otro. Esto sucede, también, cuando sentimos piedad por los muertos. 
Pensamos qué doloroso es el ser privado de la luz del sol, el carecer de vida y de trato con los demás, el yacer en una fría sepultura, presa de la degradación y de los reptiles de la tierra, el que nadie piense en nosotros en este mundo y el ser en poco tiempo apartado de los afectos y casi de la memoria de los amigos y parientes más queridos. Ciertamente, concluimos, jamás podremos sentir lo suficiente por quienes han sufrido una calamidad tan espantosa. (...) Y así surge uno de los principios más importantes de la naturaleza humana, el pavor a la muerte, el gran veneno de la felicidad humana, pero el gran freno ante la injusticia humana, que aflige y mortifica al individuo, pero resguarda y protege a la sociedad. (TSM p. 55-6)

Ante ello Smith precisa su tesis y sostiene que la simpatía "no emerge de la observación de la pasión, como de la circunstancia que la promueve". La causa de la simpatía no son los sentimientos del otro, sino el contexto en el que se encuentra, lo cual indica que la coordinación de sentimientos no es necesariamente una realidad, ya que puede ser el producto de la imaginación del observador. Esto nos conduce, aparentemente, a un callejón sin salida en este intento de explicar la génesis de la moral, pues lo que tenemos en realidad no es una comunión de sentimientos, de la que puedan derivarse normas comunes, sino un solipsismo, ya que cada uno valora la situación de acuerdo con sus propios sentimientos. La segunda persona representa meramente una proyección de la primera, un producto de la imaginación.

En este punto, Smith introduce un principio suplementario, al que denomina el placer de la simpatía recíproca, el cual postula que si bien el observador siente placer en la simpatía, es el actor quien busca más intensamente esa coordinación de sentimientos, porque la aprobación de sus posibles observadores satisface su amor propio. En el gran teatro del mundo todos asumen el papel de observador y actor; ello hace posible que cuando el observador aprueba la conducta de otros, al mismo tiempo, advierte que cuando él asume el papel de actor, también será juzgado. "Para dar lugar a dicha concordancia [de sentimientos E.S.], así como la naturaleza enseña a los espectadores a asumir las circunstancias de la persona protagonista, también instruye a esta última 
para que asuma la de los espectadores" (TSM p. 72). ${ }^{3}$ El actor tiene la ventaja de que es consciente de las dificultades que tiene el observador para ponerse en su lugar. Además, sabe que por más que se esfuerce el observador, éste nunca podrá percibir la intensidad y calidad de sus sentimientos. De ahí, que el actor aprenda que sólo puede alcanzar la simpatía si mitiga sus sentimientos, hasta el grado de que los espectadores puedan acompañarlo.

El individuo que actúa por amor propio busca la aprobación de los demás y, de esta manera, rompe con la perspectiva espontánea del egocentrismo. Smith advierte que aunque pueda ser cierto que para cada individuo sea más importante su propia felicidad que la del resto de la humanidad, nunca osará declarar que actúa bajo ese principio y evitará, en la medida de lo posible, que su comportamiento delate esa preferencia, pues ello impediría obtener la aceptación social que forma parte esencial de su propia felicidad. Por el camino del amor propio no sólo puede llegar el ser humano a controlar su egoísmo, sino también a establecer las bases de la conducta moral. El paso hacia el ámbito moral es posible cuando el individuo no sólo desea ser aprobado por los otros, sino también llegar a ser aquello que merece aprobación. Se requiere ser débil y superficial para deleitarse o encontrar satisfacción con una alabanza que no se merece. "El ser humano desea naturalmente no sólo ser amado, sino ser amable, es decir, ser lo que resulta un objeto natural y apropiado para el amor. (...) No sólo desea la alabanza, sino el ser loable, o ser un objetivo natural y adecuado para el encomio, aunque en la práctica nadie lo alabe." (TSM p. 232)

Si para cada individuo resulta importante y grato ser aprobado por los otros, su propia aprobación le resulta aún más importante. Para lograr una sólida autoaprobación el individuo requiere no sólo analizarse desde su propio punto de vista, sino también desde la supuesta perspectiva de los otros. Cada uno es, potencialmente, el mejor juez de sus

${ }^{3}$ Esta representación de la dinámica social como un sistema de espejos, que ya encontramos en Hume, representa un antecedente del interaccionismo simbólico. Ver G. M. Mead, Espíritu cultura y sociedad, 1982, Barcelona, Paidós. 
acciones, pero para llegar a actualizar esa capacidad se requiere de un entrenamiento, de un hábito, que permita superar la fácil autocomplacencia.

Nunca podemos escudriñar nuestros propios sentimientos y motivaciones, jamás podemos abrir juicio alguno sobre ellos, salvo que nos desplacemos, por decirlo así, fuera de nuestro propio punto de vista y procuremos enfocarlos desde una cierta distancia. Sólo podemos hacer esto intentando observarnos a través de los ojos de otra gente, o como es probable que otros lo contemplen. (...) Tratamos de examinar nuestra conducta tal como concebimos que lo haría cualquier espectador recto e imparcial. (TSM p. 228)

La autorreferencia indirecta, esto es, el referirse a sí mismo a través de los otros, abre la posibilidad, mediante el adiestramiento en el trato social, de transformar la perspectiva de un espectador concreto, en la de un espectador imparcial. Para expresarlo con otros términos, la experiencia de la autorreferencia indirecta puede conducir paulatinamente de la perspectiva de la segunda persona a la de la tercera, la cual define la propiedad básica de la conciencia moral. Smith describe este proceso como el paso de la conciencia del espectador externo (the man without), a la del espectador interno (the man within). El espectador interno, con pretensiones de imparcialidad, es un producto de la experiencia y, como tal, refleja en un principio el nivel de la conciencia moral promedio imperante en las relaciones sociales. Ello quiere decir que no existe una garantía a priori de que sus juicios morales sean correctos. Sin embargo, su aparición (tanto en el nivel ontogenético, como en el filogenético) representa una exigencia de imparcialidad, mediante su interacción con los otros.

La perversión de la rectitud de nuestros juicios acerca de la corrección de nuestra conducta no siempre requiere que el espectador real e imparcial se halle a una enorme distancia. Cuando está cerca y presente, la violencia e injusticia de nuestras pasiones egoístas es a veces suficiente para inducir al hombre dentro del pecho a brindar un testi- 
monio muy diferente del que las verdaderas circunstancias del caso están en condiciones de permitir. (TSM p. 288)

Smith sostiene de manera rotunda que los sentimientos y las pasiones representan los resortes de las acciones, pero destaca que existen dos momentos propicios para que el individuo analice sus actos como lo haría el espectador imparcial: Uno es cuando estamos a punto de actuar, el otro es después de haber actuado. Reconoce que en ambos casos hay una fuerte tendencia a considerar de manera parcial, unilateral, la situación. En el primer caso la intensidad y avidez de las pasiones impiden la objetividad que exige el espectador imparcial, "como dice el padre Malebranche, todas las pasiones se justifican a sí mismas, y mientras las sintamos parecen razonables y proporcionadas a sus objetos". (TSM p. 289) El segundo momento es más propicio para considerar las circunstancias fríamente, pero, una vez realizada la acción, el juicio es menos importante y, en numerosas ocasiones, sólo da lugar a un vano arrepentimiento y a una infructuosa compunción, que, normalmente, no evita cometer los mismos errores en el futuro. Por otra parte, es tan desagradable el desaprobarse que se tiende a apartar la mirada de los hechos, para buscar pretextos y excusas poco sólidas. "Este autoengaño, esa fatal debilidad de las personas, es la fuente de la mitad de los desórdenes de la vida humana." (TSM p. 290)

Si bien Smith insiste, incluso de una manera más vehemente que Hume, en que la fuente de la moral se encuentra en los sentimientos, en este punto reconoce que la labor del espectador imparcial requiere del establecimiento de reglas generales de la moral y, con ello, de la intervención de la razón. ${ }^{4}$ Estas reglas son de gran utilidad para corregir las tergiversaciones propiciadas tanto por el amor propio, como por el egoísmo, en relación al problema de lo que es justo y apropiado reali-

4 "No es el apagado poder del humanitarismo, no es el tenue destello de la benevolencia que la naturaleza humana ha encendido en el corazón humano lo que es así capaz de contrarrestar los impulsos más poderosos del amor propio. (...) Es la razón, el principio, la conciencia, el habitante del pecho, el hombre interior, el ilustre juez y árbitro de nuestra conducta." (TSM p. 260) 
zar en los distintos contextos particulares. Estas reglas son también producto de la experiencia. La continua observación de la conducta ajena permite forjar lentamente las reglas de lo que es justo y de lo que es apropiado hacer o dejar de hacer. "No aprobamos ni condenamos, inicialmente los actos concretos porque tras el examen correspondiente resulten compatibles o incompatibles con una determinada regla general. Por el contrario, la regla general se forma cuando descubrimos por experiencia que todas las acciones de una cierta clase o caracterizadas por determinadas circunstancias son aprobadas o reprobadas." (TSM p. 292$)^{5}$

La exigencia de adecuar la conducta a esas reglas generales se denomina deber, "un principio de sobresaliente importancia en la vida humana y el único principio por el cual la mayoría de la humanidad puede orientar sus acciones". (TSM 296) El problema reside ahora en establecer cuáles son los motivos que impulsan a los individuos a respetar esas reglas, esto es, a cumplir con el deber moral. La respuesta de Smith es tajante: El cumplimiento del deber es resultado de la presión que el orden social ejerce sobre el individuo.

El tosco barro con que está formado el grueso de la humanidad no puede ser labrado hasta una cumbre tan perfecta. Pero no hay persona a la que mediante la disciplina, la educación y el ejemplo no se le pueda inculcar un respeto a las reglas generales de forma tal que actúe en toda circunstancia con una aceptable decencia y que evite durante toda su vida cualquier grado considerable de reproche (...) Sin este respeto sagrado a las normas generales, no se podría confiar demasiado en la conducta de nadie. Ahí radica la diferencia más esencial entre una persona de principios y honor y el individuo más indigno. (TSM p. 298)

Sin embargo, esta respuesta no es suficiente, pues si nos conformamos con ella accedemos a una postura muy cercana a la odiosa

${ }^{5}$ Cabe señalar que Kant suscribiría gran parte de análisis genético de Adam Smith; sin embargo, insistiría que el imperativo categórico, precisamente, tiene la función de establecer la validez de esas reglas forjadas empíricamente. 
teoría de Hobbes, para quien el respeto de las leyes depende fundamentalmente de la capacidad de coacción del poder civil. Por eso, Smith acude de nuevo a la noción de amor propio y al principio del placer de la simpatía recíproca. Su tesis consiste en afirmar que los individuos requieren aprender, a través de su experiencia, que el respeto a esas reglas es la única manera de obtener la simpatía de los otros; simpatía que conforma un elemento necesario de su propia felicidad. Smith agrega que la formación moral del individuo consiste en lograr que coincidan la autoaprobación con la aprobación ajena, a través de la mediación de las reglas. La aprobación ajena puede ser considerada como un síntoma de la corrección moral, siempre y cuando no sea sólo la aprobación de los individuos que forman parte de su contexto social particular, sino de todos los seres humanos, cuya experiencia se plasma precisamente en dichas reglas.

En consecuencia, el sentir mucho por los demás y poco por nosotros mismos, el restringir nuestros impulsos egoístas y fomentar los benevolentes, constituye la perfección de la naturaleza humana; sólo así puede producirse entre los seres humanos esa armonía de sentimientos y pasiones que resume todo su donaire y corrección. Así como amar al prójimo como a nosotros mismos es la gran ley de la cristiandad, el gran precepto de la naturaleza es amarnos a nosotros mismos sólo como amamos a nuestro prójimo o, lo que es equivalente, como nuestro prójimo es capaz de amarnos. (TSM p. 76)

En este punto se encuentra un punto de unión entre la TSM y la RN. La tesis central es que en una sociedad de mercado, donde la satisfacción de las necesidades de cada individuo depende de su relación con una gran cantidad de seres humanos, muchos de los cuales no mantienen una relación cercana con él y, por tanto, a los que no puede exigir benevolencia, el respeto a las reglas morales resulta esencial. La razón de ello es que la aprobación de los otros y el prestigio que se deriva de ello, representan, como el dinero, un poder necesario para alcanzar las propias metas. La idea es que un amor propio, ilustrado por la expe- 
riencia, conduce a los individuos a los umbrales de la moral. De esta manera, se establecería una conexión entre, por un lado, la división del trabajo y la expansión del mercado y, por otro, la formación moral de los individuos, su transformación en ciudadanos.

Pero debemos tener mucho cuidado de no sacar conclusiones apresuradas, como lo hacen los apologistas de la modernidad y del libre mercado. Smith sostiene que esta relación entre modernidad y formación moral de los seres humanos es una posibilidad, un resultado contingente, que depende de muchos otros factores (básicamente políticos). Lo que él plantea es que el mercado puede aproximarse al funcionamiento del ideal de la mano invisible si y sólo si existe una infraestructura moral, objetivada en un orden institucional, que permita mantener la competencia entre los individuos en el marco de las normas de justicia que hacen posible la convivencia civilizada. Smith, al igual que Hume, afirma que la justicia es un artificio, esto es, un sistema de normas producidas por la experiencia que deben corregirse continuamente para adaptarse a las cambiantes circunstancias. Ambos coinciden también en que ese artificio es necesario. Una competencia mercantil, sin un orden civil que garantice la justicia, es decir, sin Estado de derecho, es simplemente un estado de naturaleza hobbesiano llevado a su extremo, es decir, la barbarie. Sin normas de justicia comunes, el vendedor y el comprador se convierten en enemigos absolutos, para los cuales la lucha sólo puede cesar con el pleno sometimiento de uno de ellos. La ausencia de justicia tiene como efecto que la división del trabajo y la expansión del mercado conduzca no a una sociedad de abundancia, sino a una sociedad esclavista. "En una palabra, el comercio y las manufacturas sólo pueden florecer en un Estado en que exista cierto grado de confianza en la justicia del gobierno." (RN p. 808)

${ }^{6} \mathrm{Si}$ bien es cierto que Adam Smith tiende a reducir la justicia a su aspecto negativo, esto es, a justicia conmutativa (aquella que tiene que ver con el respeto a la persona y a sus propiedades), no se olvida por completo de la faceta distributiva de la justicia. Aunque no se puede decir que Smith es un antecedente del Estado de bienestar y los derechos sociales, no hace a una lado la importancia del equilibrio en la distribución de la riqueza para el desarrollo social, de ahí, por ejemplo, su recomendación de promover la educación pública. Sobre esto ver TSM p. 482-3. 
Smith percibe que en una sociedad moderna la justicia que hace posible la convivencia pacífica no depende de la identificación afectiva de sus miembros, sino de normas abstractas, emanadas de la perspectiva de un espectador imparcial. Su optimismo respecto a que la expansión del mercado y las capacidades técnicas de la sociedad produzca la abundancia que permita satisfacer las demandas de la justicia distributiva depende de su confianza en la tradición constitucionalista, que se desarrolla en la tradición política inglesa.

Hasta ahora hemos reconstruido el aspecto que podemos llamar positivo de su teoría de la formación moral de los individuos, pero esta narración incluye otra faceta.

\section{La corrupción de los sentimientos morales}

La genealogía de la conciencia moral que se ha reconstruido aquí de manera breve es una narración conjetural, esquemática, que permite determinar los pasos que son necesarios para que las acciones basadas en el amor propio conduzcan a la moral. Pero Smith, como hemos dicho, nunca pierde de vista que el devenir histórico es mucho más complejo y que, por tanto, no se pueden hacer predicciones a la ligera. De hecho, al igual que en la RN encontramos una amplia lista de casos en los que es necesario hacer excepciones de la doctrina del laissez-faire, en la TSM es posible localizar numerosos obstáculos que impiden la correcta evolución de la simpatía. Para responder a las exigencias del conocimiento empírico tenemos que tomar en cuenta otros elementos que explican las variaciones y desviaciones del esquema expuesto sobre la evolución de la conciencia moral.

El primer gran obstáculo en la correcta formación de la conciencia moral es la envidia, esto es, una pasión ligada al egoísmo que ve con "ojos malignos la superioridad de quienes realmente merecen toda la superioridad que ostentan". (TSM p. 436) La envidia impide que la simpatía pueda cumplir con su función de regulación moral, ya que la primera tiende a la oposición de los sentimientos y no a la concordan- 
cia. Para Smith es tan importante este factor, que cuando habla de los beneficios de la simpatía, generalmente lo hace de manera condicional ("... cuando no hay envidia...", "siempre que no lo obstaculice la envidia...”, etc.). Según él la propensión a la envidia es mayor entre personas que se consideran iguales; por eso, en la sociedades modernas, en las que desaparecen las tradicionales jerarquías, ésta suele proliferar. También en profesiones en las que no existen criterios precisos de evaluación tiende a incrementarse, como sería el caso de los artistas.

Como hemos destacado, para Smith la manera correcta de emitir un juicio de aprobación de las acciones implicar dar una prioridad a los motivos; sin embargo, reconoce que la tendencia de los seres humanos es a juzgarlas por sus consecuencias. Paralelamente, él advierte que, aunque el sentido original de la noción de simpatía denota la concordancia de sentimientos en relación con el padecer, los individuos prefieren simpatizar con la dicha de los otros. A partir de estas dos premisas Smith concluye que existe una disposición humana a admirar a los ricos y poderosos, así como a despreciar o, por lo menos, a ignorar a las personas pobres o de modesta condición. Disposición que representa otra de las causas más importantes de la corrupción de los sentimientos morales. Porque se atribuye a los poderosos capacidades y virtudes que frecuentemente no poseen $y$, en cambio, a considerar a la pobreza como síntomas de vicio y estupidez, lo que muchas veces es injusto.

El exigir que las acciones sean aprobadas por su motivos y no por sus consecuencias significa que los individuos deben ser juzgados por aquello que realmente depende de su voluntad, aquello que de manera correcta puede ser imputado al actor; pues, en numerosas ocasiones, las consecuencias de los actos son el resultado de factores ajenos al arbitrio individual. Pensemos en alguien que hereda una fortuna o el trono, o bien en todos aquellos que obtienen poder mediante acciones injustas, que han permanecido impunes.

La manera que Smith evalúa la corrupción de los sentimientos morales es ambigua, porque nunca deja de reconocer que se trata de un mal, pero, al mismo tiempo, subraya que tiene cierta utilidad social. Por ejemplo la tendencia a juzgar las acciones por sus resultados y 
no por sus motivos tiene dos ventajas: 1) Evita el castigar a los individuos por sus intenciones o afectos, con ello se impide una tiranía bárbara e insolente que convertiría a todo tribunal judicial en una verdadera inquisición. 2) Dar un mayor peso a los resultados impulsa a la acción, pues hace que nadie quede satisfecho con la indolencia benévola, ni que se considere amigo de la humanidad tan sólo porque en el fondo del corazón desea el bien a todos. Por su parte, la envidia y la admiración por la riqueza son factores que estimulan la ambición y la codicia, así como a considerar que los placeres que producen el dinero y el poder son los más elevados que puede sentir un ser humano. "Y está bien que la naturaleza nos engañe de esta manera. Esta superchería es lo que despierta y mantiene en continuo movimiento la laboriosidad de los humanos." (TSM p. 332)

En el contexto de esta argumentación de la TSM se habla por primera vez de una mano invisible. La tesis es que la avaricia y afán de saciar vanos deseos lleva a producir un nivel de riqueza que permite que ésta alcance para todos. En cierta manera, se trata de un argumento cercano al que desarrolla de una manera provocativa Mandeville en su famosa Fábula de la abejas.

Los ricos sólo seleccionan lo que es más precioso y agradable. Ellos consumen apenas más que los pobres, y a pesar de su natural egoísmo y avaricia, aunque sólo buscan su propia conveniencia, aunque el único fin que se proponen es la satisfacción de sus propios vanos e insaciables deseos, dividen con los pobres el fruto de todas sus propiedades. Una mano invisible los conduce a realizar casi la misma distribución de las cosas necesarias para la vida que habría tenido lugar si la tierra hubiese sido dividida en porciones iguales entre sus habitantes, y así sin pretenderlo, sin saberlo, promueven, el interés de la sociedad y aportan medios para la multiplicación de la especie. (TSM p. 333)

Si sacamos de contexto esta idea, como lo han hecho algunos defensores del capitalismo salvaje, tenemos un bonito cuento para tranquilizar las conciencias de aquellos que tienen los medios para dedicarse a perseguir sus vanos deseos. Este cuento no sólo está muy alejado de la 
realidad, sino que también no responde a la postura de Smith, entre otras cosas, porque tornaría inútil su análisis genético de la conciencia moral. ¿Para qué preocuparse de la moral y sus normas si el egoísmo y la ambición producen un grado de riqueza tal que hace posible acceder a la justicia espontáneamente? Sin embargo, creer que ésta es la posición de Smith es pasar por alto un aspecto fundamental de su teoría.

Mientras Mandeville afirma que el egoísmo y la vanidad favorecen la productividad de la sociedad ("vicios privados, virtudes públicas"), la postura de Smith sostiene que el amor propio puede conducir a la prosperidad social, pero también, cuando se transforma en egoísmo, puede conducirla a la ruina. El que se acceda a uno u otro extremo de la alternativa depende de la existencia o ausencia de un orden civil que garantice la justicia en las relaciones sociales. Es adecuado valorar la utilidad de las acciones, siempre y cuando esta utilidad no transgreda las normas de justicia que hacen posible la convivencia civilizada. Una acción puede ser útil a corto o mediano plazo, pero si es injusta tenderá, a largo plazo, a romper con los equilibrios sociales $\mathrm{y}$, con ello, a favorecer la violencia. Es útil que los individuos persigan libremente sus intereses particulares en la dinámica mercantil, pero para que esto sea compatible con el progreso social se requiere tanto un sistema institucional que garantice la justicia, como una amplia cultura cívica. Elementos indispensables para mantener las pasiones egoístas en los cauces adecuados.

Para acceder a esa envidiable situación [de riqueza y poder E.S.], los candidatos a la fortuna con demasiada frecuencia abandonan las sendas de la virtud; porque lamentablemente el camino que conduce a la una y el que lleva a la otra se hallan a veces en direcciones muy opuestas. Pero el hombre ambicioso se hace la ilusión de que en el espléndido escenario hacia el que avanza tendrá tantos medios para atraer el respeto y la admiración de los demás, y podrá actuar con propiedad y gracia tan superiores, que el lustre de su conducta futura tapará por completo o borrará la pestilencia de los pasos a través de los cuales arribó a esas alturas. (TSM p. 143) 
El optimismo ingenuo de los primeros defensores del capitalismo y el optimismo nada ingenuo de cierto neoliberalismo reciente se sustenta en el presupuesto de una conexión necesaria entre expansión del mercado y prosperidad social, la cual se transformaría casi automáticamente en justicia. Sin embargo, esto no coincide con la teoría de Smith, para él la justicia no es producto espontáneo del sistema de intercambio mercantil, sino un artificio que requiere la formación moral de los individuos y su esfuerzo consciente por hacer efectiva las leyes mediante un orden institucional y una cultura política. Si volvemos a la narración conjetural sobre la genealogía de la conciencia moral podemos advertir que el paso esencial en este proceso es la transformación del observador externo (the man without), constituido por el conjunto de individuos que conforma el contexto social en el que se mueve el actor, en un observador interno (the man within), el gran semidiós dentro del pecho, el ilustre juez y árbitro, que representa la conciencia moral autónoma. Autonomía conquistada gracias a la experiencia en el trato social y la actividad de la razón.

Pero aunque el hombre ha sido de esta manera convertido en juez inmediato de la humanidad, lo es sólo en la primera instancia, y sus sentencias pueden ser apeladas a un tribunal mucho más alto, el tribunal de sus propias conciencias, el de supuesto espectador imparcial y bien informado, el del hombre dentro del pecho, el alto juez y árbitro de su conducta. Las jurisdicciones de esos dos tribunales se basan en principios que en algunos aspectos se parecen y son afines, pero en otros son en verdad desiguales y específicos. La jurisdicción del hombre exterior se funda exclusivamente en el deseo del elogio de hecho y en la aversión al reproche de hecho. La jurisdicción del hombre interior se funda exclusivamente en el deseo de ser loable y en la aversión de ser reprobable, en el deseo de poseer las cualidades y realizar las acciones que apreciamos y admiramos en otras personas, y en el pavor a poseer las cualidades y realizar las acciones que odiamos y despreciamos en otras personas. (TSM p. 251-2) 
En una sociedad donde el orden institucional no garantice el respeto a las normas de justicia, el comportarse virtuosamente resulta imprudente, porque el individuo que respeta las normas tiene un comportamiento predecible y, por tanto, se convierte en una fácil presa (resulta insensato comportarse como un cordero en un mundo de lobos). En esa situación el paso esencial en la formación de la conciencia moral, aunque no es imposible, resulta extremadamente difícil para la mayoría de los individuos. Son los individuos y los grupos que sufren la injusticia los que pueden cuestionar las condiciones reinantes, aunque la posición de dominado tampoco es una garantía de acceso a la conciencia moral. Por otra parte, si no existen reglas que permitan valorar de manera equitativa el mérito de los individuos, éstos no asumirán las actividades necesarias para acceder a la prosperidad social. Por el contrario, la falta de equidad favorece que a los individuos ya no les interese ser dignos de ser aprobados, sino únicamente parecerlo, es decir, quedan atrapados en la legislación del observador externo.

Como ejemplo de la corrupción moral que produce el quedar atrapados en la legislación del observador externo Smith menciona la situación que reina en una sociedad cortesana. En ella los juicios de aprobación no se basan en la simpatía de pares informados e inteligentes, sino en el favor caprichoso de superiores, dominados por la soberbia. En la dinámica cortesana la adulación y la hipocresía predominan sobre el mérito y la capacidad. "En tales sociedades el talento para agradar es mejor considerado que el talento para servir." (TSM p. 141) En las sociedades cortesanas, como en todas aquellas que predomina la legislación del observador externo, la corrupción de los sentimientos morales, lejos de generar una utilidad social, se convierte en un obstáculo para el desarrollo.

Smith coincide con Mandeville en su crítica a los moralistas tradicionales y reconoce que la corrupción de los sentimientos sociales puede llegar a generar una utilidad social. Sin embargo, entre ambos autores existen grandes diferencias. Para empezar Smith desarma el fundamento de la estrategia irónica de Mandeville, pues afirma que los llamados por este último vicios privados no son tales, se trata 
simplemente del amor propio, el cual, considerado en sí mismo, es moralmente neutral. ${ }^{7}$ La cuestión fundamental es la manera en que la sociedad encauza ese amor propio. En la medida que exista en la sociedad un orden civil que garantice el respeto a las normas de justicia, la competencia que genera el amor propio de los individuos puede convertirse en un estímulo al progreso social. Incluso, en la medida en que exista esa infraestructura moral, encarnada en las instituciones políticas, la sociedad puede tolerar un cierto grado de corrupción de los sentimientos morales y hasta extraer un beneficio de ella. Pero sin esa infraestructura el amor propio, lejos de permitir la formación de la conciencia moral, degenera en egoísmo y éste conduce a una confrontación generalizada, en donde la ausencia de justicia impide el desarrollo económico y social en general.

\section{La infraestructura moral de la competencia democrática}

Darse cuenta de la validez relativa de las convicciones propias y, no obstante, defenderlas resueltamente, es lo que distingue a un ser humano civilizado de un bárbaro.

Schumpeter

Una de las estrategias que utilizaron los sistemas totalitarios del siglo XX consistió en cuestionar las democracias existentes, calificadas como liberales o representativas, en nombre de una supuesta democracia auténtica. El punto de partida de dicha estrategia consiste en destacar

7 "La gran falacia del libro del Dr. Mandeville estriba en que representa cualquier pasión como plenamente viciosa, en cualquier grado y cualquier sentido (...). El auténtico fundamento de este sistema licencioso se encuentra en algunas doctrinas ascéticas populares que florecieron antes de su época, según las cuales la virtud consistía en la completa extirpación y aniquilamiento de todas nuestras pasiones. Al Dr. Mandeville le resultó sencillo probar, primero, que esa conquista plena jamás tuvo lugar entre los seres humanos, y segundo, que si tenía lugar de manera universal sería perniciosa para la sociedad, porque pondría fin a toda industria y comercio, y en cierto sentido a toda la actividad de la vida humana." (TSM p. 543-4) 
la inadecuación entre los valores democráticos y su realidad institucional, para, posteriormente, justificar prácticas autoritarias como el medio más adecuado para acceder a la realización plena de esos valores. La eficacia de este uso ilegítimo de los valores democráticos, tan extendido en nuestros días, depende de no advertir que el reconocimiento de esa inadecuación es, precisamente, una de las características básicas de los sistemas democráticos. Asumir la imposibilidad de superar por completo el abismo entre el ser y el deber ser, abandonar los sueños utópicos de perfección, propicia que se acepte la necesidad de reformar de manera constante el orden democrático, con el objetivo de responder a las exigencias complejas y, a veces, contradictorias de los valores democráticos. ${ }^{8}$ La democracia no se plantea como una panacea que resuelve todos los problemas sociales, sino como un escenario que permite representar de manera controlada, no violenta, las tensiones y conflictos que emanan de esos problemas, con el objetivo de buscar alternativas y tomar decisiones sustentadas en un amplio consenso.

Ante la experiencia del uso ilegítimo de los valores democráticos, Schumpeter realiza una crítica de lo que él llama la teoría clásica de la democracia, la cual ofrece el discurso que hace posible utilizar los valores democráticos para desprestigiar las instituciones y los procedimientos de las democracias existentes. Una vez realizada esta crítica, se propone ofrecer las bases para desarrollar una teoría compatible con la experiencia, esto es, una teoría que pueda dar cuenta de la dinámica de las democracias que conocemos. Para cumplir esta tarea establece una analogía entre el mercado y la democracia, lo que le permite caracterizar a esta última como un método para tomar decisiones, en donde una diversidad de grupos, generalmente constituidos por políticos

8 "La democracia se revela así como la sociedad histórica por excelencia, sociedad que, en su forma, acoge y preserva la indeterminación, en notable contraste con el totalitarismo que edificándose bajo el signo del hombre nuevo, en realidad se erige en contra de esta indeterminación, pretendiendo detentar la ley de su organización y de su desarrollo, y se dibuja secretamente en el mundo moderno como sociedad sin historia." Lefort, C. "La cuestión de la democracia", en Ensayos sobre lo político, 1991, Guadalajara, U. de G., p. 25. 
profesionales, buscan acceder al control del poder estatal mediante una competencia por el voto del pueblo. ${ }^{9}$

Sin duda la propuesta de Schumpeter tuvo éxito, basta recordar el vigor de la tradición de las teorías empíricas de la democracia. Sin embargo, la manera en la que Schumpeter expone su teoría propició la aparición de un falso dilema entre una noción descriptiva y una prescriptiva de la democracia. Su argumentación comienza con la invitación a realizar un experimento mental: "Trasladémonos a un país hipotético, en el cual, por procedimientos democráticos se persiga a cristianos, se condene a la hoguera a las personas acusadas de hechicería y se dé muerte a los judíos." Posteriormente formula la siguiente pregunta retórica “¿Aprobaríamos la constitución democrática que dio origen a tales resultados, o nos inclinaríamos más bien por una constitución no democrática que pudiera evitarlos?" El objetivo de este experimento es hacer patente que la democracia es, ante todo, un método para llegar a decisiones políticas, por lo que no puede considerarse como un fin en sí misma. "Entre otras cosas revela el hecho de que la relación entre la democracia y la libertad tiene que ser considerablemente más compleja de lo que solemos creer." (Schumpeter 1983 p. 315)

El problema de dicho experimento mental es la imposibilidad de admitir que la constitución de ese hipotético país, que autoriza la persecución de las minorías, pueda ser calificada de democrática. Sin duda Schumpeter tiene razón respecto a que idealizar la democracia es un peligro. El desligar lo deseable de lo posible, para caracterizar a la democracia a partir de sus valores, crea las condiciones para cometer las peores atrocidades en su nombre. También acierta en plantear la necesidad de iniciar el análisis de la democracia a partir del procedimiento que la ha caracterizado en el mundo moderno, a saber: Los procesos electorales. Pero el error reside en considerar que su teoría

9 "La democracia significa tan sólo que el pueblo tiene la oportunidad de aceptar o rechazar los seres humanos que han de gobernarle. Pero como el pueblo puede decidir esto también por medios no democráticos, hemos tenido que estrechar nuestra definición añadiendo otro criterio identificador del método democrático, a saber: La libre competencia entre los pretendientes al caudillaje por el voto del electorado." (Schumpeter 1983 p. 362) 
del caudillaje político ofrece una definición de la democracia. Lo que su teoría brinda es un criterio para diferenciar empíricamente entre los gobiernos democráticos y aquellos que sólo dicen serlo. La presencia de procesos electorales competitivos es una condición necesaria, pero no una condición suficiente para la existencia de un régimen democrático.

Si queremos acceder a una teoría de la democracia capaz de describir la complejidad de su dinámica es preciso explicar la relación entre el orden institucional y su nivel normativo. Los valores asociados a la democracia no son adornos retóricos, ni simples medios para condensar información. La vigencia de esos valores, incluyendo las tensiones que existen entre ellos, son el lubricante indispensable que hace funcionar de manera adecuada a las instituciones y los procedimientos democráticos. Podemos aceptar la analogía entre mercado y democracia, a condición de tomar en cuenta las observaciones que realiza Adam Smith sobre los requisitos necesarios para que la competencia sea compatible con el desarrollo social. La competencia, ya sea mercantil o política, sin una infraestructura moral sólo conduce a la barbarie. Recordemos que para Adam Smith el funcionamiento del mercado sólo puede aproximarse al ideal de la mano invisible si existe un marco institucional y una cultura política que garantice la justicia. Las condiciones imperantes en muchas democracias recientes son una prueba de esta tesis. El propio Adam Smith ya había advertido que los procesos electorales sustentados en una legislación fundamentada en la perspectiva de un observador externo, es decir, una legislación que no cumple con las exigencias de justicia propias del observador imparcial, se convierten en el paraíso de los demagogos y de los artistas del fraude.

En muchos Estados, los candidatos para los cargos más importantes están por encima de la ley; y si pueden alcanzar el objeto de su ambición, no temen que deban rendir cuentas de los medios merced a los cuales los consiguieron. Por ello, repetidamente procuran suplantar y destruir a quienes se les oponen o se interponen en su camino hacia el poder, no sólo mediante el fraude y la falsedad, las artes ordinarias y vulgares de la intriga y la maquinación, sino a veces mediante la perpe- 
tración de los delitos más monstruosos, el crimen y el asesinato, la rebelión y la guerra civil. (TSM p. 143)

Antes de que Adam Smith expusiera su teoría sobre la génesis de la conciencia moral como infraestructura indispensable de la competencia social, Montesquieu había destacado la necesidad de distinguir entre la naturaleza y el principio de cualquier gobierno: "La naturaleza es lo que le hace ser tal, el principio lo que le hace actuar; la naturaleza es su estructura particular; el principio, las pasiones humanas que le ponen en movimiento." (Montesquieu 1980 p. 63) En el caso de las repúblicas democráticas, su naturaleza remite a la división de poderes y a los procesos electorales competitivos, entre otros elementos; mientras que su principio se encuentra en la virtud de los ciudadanos. Sin embargo, en consonancia con una concepción republicana trasnochada, Montesquieu entiende la virtud del ciudadano como una especie de sacrificio del individuo en el altar de la patria o de un supuesto bien común. En cambio, de acuerdo al análisis de la génesis de la conciencia moral que realiza Smith, la virtud ciudadana no implica el sacrificio del amor propio del individuo; por el contrario, se trata de ilustrar o formar ese amor propio para que el individuo trascienda la tendencia al egoísmo y, de esta manera, adquiera la capacidad de hacer un cálculo de su interés a largo plazo.

Cabe destacar que el mismo Schumpeter, a pesar de su planteamiento confuso, habla de las condiciones para el éxito del método democrático. Desde su punto de vista estas condiciones son cuatro (Schumpeter 1983 p. 368-76)

La primera condición consiste en que el material humano de la política-los seres humanos que componen los organismos de los partidos, los que son elegidos para servir en el parlamento o los que ascienden a los cargos del gabinete- debe ser de una calidad suficientemente elevada.

La segunda condición para el éxito del método democrático consiste en que el dominio efectivo de la decisión política no debe ser demasiado dilatado. Con ello Schumpeter se refiere a que es necesaria la 
existencia de ciertos principios que se sitúen por encima de la competencia electoral y de las decisiones de un gobierno particular. Se trata de principios que permiten mantener la libertad y un cierto grado de equilibrio en la competencia política. En esta condición se puede incluir la vigencia de un Estado de Derecho. (A partir de esta segunda condición él mismo se vería en la necesidad de reconocer que la constitución de su hipotético país no puede ser calificada de democrática.)

Como tercera condición, el gobierno democrático debe poder disponer, para todos los objetivos incluidos en la esfera política, de los servicios de una burocracia bien capacitada que goce de buena reputación y se apoye en una sólida tradición dotada de un fuerte sentido del deber y de un esprit de corps no menos fuerte.

El cuarto componente de condiciones puede compendiarse en la frase autodisciplina democrática. Como parte de este grupo de condiciones se menciona la existencia de una oposición responsable, la independencia o autonomía de los representantes del pueblo, así como un elevado grado de tolerancia.

Schumpeter olvida un quinto grupo de condiciones, las cuales pueden reunirse bajo el concepto de sociedad civil. Este grupo hace referencia a la participación ciudadana más allá de los procesos electorales. Este olvido no es un simple accidente, sino un efecto que se deriva del núcleo de su posición teórica. Schumpeter asume los presupuestos teóricos de lo que podemos llamar un pluralismo abstracto, ${ }^{10}$ para el cual la multiplicidad de intereses y preferencias son una variable exógena al sistema político, un dato prepolítico, que debe ser reflejado tanto en la competencia electoral, como en el proceso legislativo. Por otro lado, la participación política de los ciudadanos lejos de verse como un bien, es considerada un fenómeno que puede alterar los equilibrios sociales y generar una situación de ingobernabilidad. De hecho la falta de participación es vista como una expresión de satisfacción. El carácter abstracto de esta modalidad de pluralismo consiste en que

${ }^{10}$ Gran parte de estos presupuestos serán adoptados también por los representantes del pluralismo que imperó en la ciencia política norteamericana a partir de los años sesenta. Autores como: Dahl, Bentley, Truman, etc. 
ofrece una imagen inmóvil de la sociedad o, quizá sea más preciso decir, una visión de la dinámica política ajena a las transformaciones históricas, en la que no se cuestiona la formación y validez de los intereses y las preferencias. ${ }^{11}$

Schumpeter adopta estos presupuestos debido, en gran parte, a la desconfianza que siente ante la naturaleza humana en la política. ${ }^{12} \mathrm{Sin}$ duda esta desconfianza tiene una base empírica importante y, además, gran parte de los intentos de transformar dicha naturaleza a través de los medios políticos lejos de tener éxito, ha conducido a grandes catástrofes. Sin embargo, más allá de los presupuestos antropológicos, si queremos ser coherentes con una teoría descriptiva de la democracia, encontramos que la teoría de la competencia por el caudillaje político de este autor no nos ofrece los medios suficientes. Schumpeter admite que el funcionamiento adecuado del método democrático requiere que se cumplan las condiciones que hemos mencionado y, en relación con el quinto grupo de condiciones, agrega lo siguiente: "Hemos subrayado que no puede esperarse que la democracia funcione satisfactoriamente, a menos que la gran mayoría de la población de todas las clases esté dispuesta a atenerse a las reglas del juego democrático, y que esto implica, a su vez, que estos ciudadanos han de estar substancialmente de acuerdo sobre los fundamentos de su estructura institucional." (Schumpeter 1983 p. 382)

11 "La existencia de preferencias objetables o distorsionadas sugiere que la política no debería poner en práctica simplemente los deseos de los ciudadanos, sino que también debería permitir que hubiera cierta distancia crítica y análisis de esos deseos, teniendo en cuenta información nueva y distintas perspectivas." Sunstein, Cass R. "Más allá del resurgimiento republicano", en Ovejero, Martí y Gargarella, Nuevas ideas republicanas, 2004, Barcelona, Paidós.

12 "El debilitamiento del sentido de la responsabilidad y la falta de voliciones efectivas explican a su vez esta ignorancia del ciudadano corriente y la falta de juicio en cuestiones de política nacional y extranjera; que son más sorprendentes, si esto puede sorprender, en el caso de personas instruidas y de personas que actúan con éxito en situaciones de la vida ajenas a la política que en el caso de personas poco instruidas y de condición humilde. (...) Así, pues, el ciudadano normal desciende a un nivel inferior de prestación mental tan pronto como penetra en el campo de la política. Argumenta y analiza de una manera que él mismo calificaría de infantil si estuviese dentro de la esfera de sus intereses efectivos. Se hace de nuevo primitivo." (Schumpeter 1983 p. 335) 
Pero Schumpeter no explica la génesis de las condiciones necesarias para el buen funcionamiento de la democracia, entre las que se encuentra el respeto a la legalidad e identificación con los fundamentos de la estructura institucional. Si queremos lograr este objetivo es menester abandonar el modelo en donde se considera a los ciudadanos como simples receptores pasivos de las ofertas que proponen las élites políticas en su competencia por el poder político. Si se quiere mantener la analogía entre el mercado y la democracia, como un recurso descriptivo, se requiere recuperar la tesis de Adam Smith según la cual todos los participantes deben tomar un papel activo en el proceso de formación de las preferencias colectivas. No se requiere negar la dicotomía élites y masas o, mejor, políticos profesionales y ciudadanos en general; pero es indispensable abandonar la idea de intereses y preferencias como un hecho ajeno a la dinámica política. Se trata de captar el mercado político como una realidad en continua transformación, en donde, si bien los políticos profesionales quieren imponer ciertos intereses, también existe una resistencia por parte del pueblo. Precisamente la competencia política horizontal, esto es, entre grupos de políticos profesionales o, incluso, entre grupos de ciudadanos, como el conflicto político en su dimensión vertical, es decir, entre gobernantes y gobernados, es lo que abre la posibilidad de un proceso de formación de los intereses y las preferencias, ante las exigencias de los valores democráticos. De acuerdo con esto, la amplia participación ciudadana, aunque implica riesgos, es también un requisito indispensable para la constitución de las condiciones que permiten el funcionamiento adecuado del método democrático y su sistema representativo.

El método genético (la historia conjetural) de Adam Smith representa el medio para construir una teoría descriptiva capaz de captar la función e importancia de los valores en la dinámica democrática. Para que exista un sistema democrático, se requiere de procesos electorales competitivos, pero también se requiere de muchas otras cosas. Es menester entender, como diría Montesquieu, la naturaleza y el principio de la democracia. Es la tensión insuperable entre la realidad institucional y el nivel normativo, lo que hace de la democracia un régimen 
abierto, de manera permanente, a las reformas. Mientras Schumpeter afirma que es necesario reconocer que "las democracias son como deben ser", Smith sostiene que para juzgar a una democracia se requiere, al igual que para emitir un juicio sobre nosotros mismos, de dos patrones dispares:

Uno es la idea de la exacta propiedad y perfección, en la medida en que cada uno de nosotros sea capaz de percibir esta noción. El otro es el nivel de aproximación a esta idea que es comúnmente alcanzado en el mundo y que de hecho ha sido alcanzado por el grueso de nuestros amigos y compañeros, rivales y competidores. (...) La persona sabia y virtuosa dirige su atención principalmente al primer patrón: La idea de la exacta propiedad y perfección. En cada ser humano, late una noción de este tipo, formada gradualmente a partir de sus observaciones del carácter y proceder tanto de él mismo como de otros. Es la obra lenta, gradual y progresiva del gran semidiós dentro del pecho, el ilustre juez y árbitro de la conducta. (TSM p. 441-2)

El uso de estos dos patrones de manera simultánea no sólo aumenta la capacidad descriptiva de una teoría, al mismo tiempo abre la posibilidad de introducir una perspectiva crítica. Ahora bien, una teoría crítica no implica únicamente el contraste entre el ser y el deber, es decir, entre estos dos patrones, sino que, al mismo tiempo, se esfuerza en establecer las condiciones que hacen posible aproximar la realidad social a las exigencias normativas. Es en este punto donde tiene su lugar la teoría jurídica de Adam Smith. En las últimas líneas de la TSM se hace la siguiente promesa: "En otro estudio procuraré explicar los principios generales del derecho y el Estado, así como de los grandes cambios que han experimentado a lo largo de los diversos períodos y etapas de la sociedad, no sólo en lo relativo a la justicia sino en lo que atañe a la administración, las finanzas públicas, la defensa y todo lo que cae bajo el ámbito legislativo.” (TSM p. 595) Aunque Smith no cumple esta promesa, conservamos los apuntes de sus Lecciones sobre jurisprudencia, a partir de los cuales se puede reconstruir la línea argumentativa de dicho estudio. 
Al igual que Hume, Adam Smith rechaza la tesis de que los principios de justicia se fundamenten en un orden trascendente o ajeno a la voluntad de los seres humanos. Tanto Hume como Adam Smith consideran a la justicia como un artificio social, con ello quieren decir que las normas de justicia no dependen de un orden trascendente, ni de la voluntad divina. Sin embargo, afirmar que la justicia es un artificio o una convención social no implica decir que su contenido sea arbitrario y ajeno a las exigencias de la razón. Mientras Hume se esfuerza en demostrar que las condiciones imperantes en el mundo humano hacen necesaria la justicia para regular las relaciones sociales, por su parte, Adam Smith en su análisis de la conciencia moral pone de manifiesto que sí existe un criterio racional para juzgar críticamente la multiplicidad de normas positivas de justicia. Dicho criterio es la perspectiva del espectador imparcial, la cual representa un procedimiento para revisar de manera continua nuestras creencias en torno a la justicia.

En su teoría del derecho, Smith se propone determinar las condiciones para que esa perspectiva del espectador imparcial encarne en el nivel institucional de la sociedad y, de esta manera, se convierta en un elemento relevante en las acciones individuales. Podemos decir que el derecho es para Adam Smith el recurso central para que los principios morales y la conciencia que los acompaña adquieran una eficacia en la dinámica social. A diferencia del iusnaturalismo tradicional, este autor afirma que, en términos genéticos, si bien no existe una conexión necesaria entre derecho y moral, se requiere crear esa conexión para hacer posible la constitución de la infraestructura que permita compaginar la competencia, tanto económica como política, con la estabilidad del orden civil de la sociedad y con las exigencias de justicia. Mientras no exista esa infraestructura moral, objetivada en el sistema jurídico, los mercados económicos y políticos no contribuirán al desarrollo de la sociedad. $^{13}$

${ }^{13}$ Adentrarse en la comprensión de la génesis y funcionamiento de la infraestructura moral del mercado y la democracia, por tanto, requiere introducir otras variables. Reconstruir la teoría jurídica de Adam Smith representa un recurso para determinar dichas variables, tarea que reservo para un trabajo futuro. 


\section{Bibliografía}

Blaug, Mark, Teoría económica en retrospección, 2001, México, FCE.

Ferguson, John M., Historia de la economía, 2001, México, FCE.

Dupuy, Jean-Pierre, El sacrificio y la envidia, 1998, Barcelona, Gedisa.

Garzón Valdés, E., Instituciones suicidas, 2000, México, Paidós.

Hirschman, Albert O., Las pasiones y los intereses, 1978, México, FCE.

Lefort, C., Ensayos sobre lo político, 1991, Guadalajara, U. de G.

Mandeville, Bernard, La fábula de las abejas, 2001, México, FCE.

Montesquieu, Del espiritu de las leyes, 1980, Madrid, Tecnos.

Raphael, D.D., Adam Smith, 1985, Oxford, University Press.

Rodríguez Lluesma, C., Los modales de la pasión, 1997, Navarra, EUNSA.

Schumpeter, J. A., Capitalismo, socialismo y democracia, 1983, Barcelona, Orbis.

Smith, Adam, Investigación sobre la naturaleza y causas de la riqueza de las naciones.

(RN), 1984, México, FCE.

, Teoría de los sentimientos morales, 1997, Madrid, Alianza.

, Lecciones sobre jurisprudencia, 1995, Granada, COMARES. 
La reproducción total o parcial de este artículo se podrá hacer si el ITAM otorga la autorización previamente por escrito. 